\title{
Equilibrium Study on Interactions between Proteins and Bile-Salt Micelles by Micellar Electrokinetic Chromatography
}

\author{
Tohru SaItoh, Teruyuki Fukuda, Hirofumi Tani, Tamio Kamidate \\ and Hiroto WatanaBe
}

Faculty of Engineering, Hokkaido University, Sapporo 060, Japan

\begin{abstract}
Interactions between proteins and bile-salt micelles were evaluated on the basis of the binding constants, which were obtained from the migration of proteins in micellar electrokinetic chromatography. The binding constants, $K_{b}=\left[P_{b}\right] /$ $\left(\left[P_{w}\right][B]\right)$, where $\left[P_{b}\right]$ is the concentration of a protein binding with a bile-salt, $\left[P_{w}\right]$ free protein concentration, and $[B]$ the concentration of bile salt present in the micelles, were successfully determined from the slope of a linear curve of the capacity factor $(k)$ of the protein against [B]. The binding constants were almost identical to those obtained by a gelfiltration method. The value of $K_{\mathrm{b}}$ increased with increasing the hydrophobicity of the bile salt or that of the protein.
\end{abstract}

Keywords Protein, bile-salt micelle, binding constant, micellar electrokinetic chromatography

Bile salts have been extensively used in several steps of protein purification, such as the selective solubilization of membranes, the chromatographic separation of proteins, and the reconstitution of proteins. ${ }^{1-5} \mathrm{~A}$ predominant factor controlling the separation efficiency of protein purification is the interactive nature between the proteins and the bile-salt micelles. Therefore, a quantitative description of protein-micelle interactions is necessary for designing micellar-mediated separation methods.

Tanford et al. ${ }^{6,7}$ determined the binding constants for interactions between some proteins and bile-salt molecules using equilibrium dialysis and gel-filtration methods. However, these methods are both tedious and time consuming. In addition, few quantitative data describing the exact nature of the protein-micelle interactions have yet been obtained. Thus, a rapid and simple method is desirable for evaluating the equilibrium constants for the interactions.

In this study, we tested the use of micellar electrokinetic chromatography (MEKC) for determining the binding constants between the proteins and bile salts in aqueous micellar solutions. The constants agreed well with those obtained by the gel-filtration method. Furthermore, we discuss the relationship between the protein-micelle interaction and the hydrophobic properties of a bile salt or protein, based on the binding constants.

T. S. present address: Tokyo University of Pharmacy \& Life Science, 1432-1 Horinouchi, Hachioji, Tokyo 192-03, Japan.

\section{Experimental}

\section{Apparatus}

An MEKC instrument was made in a manner similar to that reported by Terabe et al. ${ }^{8-10}$ The instrument comprised a fused silica capillary tubing with an internal diameter of $50 \mu \mathrm{m}$ and a total length of $65 \mathrm{~cm}$; detection was made $50 \mathrm{~cm}$ downstream. The detector was a JASCO UVIDEC-100 II type UV detector with a modified flow-cell compartment. A high voltage (0$20 \mathrm{kV}$ ) was supplied by Matsusada Precision Devises (HCZE-30PN0.25 high voltage power supply). The temperature was maintained at $25 \pm 1^{\circ} \mathrm{C}$.

\section{Materials}

Bile salts and proteins were obtained from Sigma Chemical Co. They were sodium cholate (SC), sodium deoxycholate (SDC), sodium taurocholate (STC), sodium taurodeoxycholate (STDC), albumin (bovin serum), ovalbumin (chicken egg), myoglobin (horse heart), trypsin (bovin pancreas), lysozyme (chicken egg white), chytochrome $c$ (horse heart), and $\beta$-lactogloblin B (bovin milk). Cytochrome $b_{5}$ and $\mathrm{P} 450$ were purified by Kamataki's method. ${ }^{3}$ 3-(Cycrohexyl)propanesulfonic acid (CAPS) was used as a buffer component. Sucrose and Sudan III were used as marker reagents for the solvent and micelles, respectively.

\section{$M E K C$ separation of proteins}

The solution used for protein separation was an aqueous CAPS (0.01 M, pH 11.0) buffer solution containing bile salt $(0-50 \mathrm{mM})$. Electroinjection $(10 \mathrm{kV}$ for $10 \mathrm{~s}$ ) was performed in order to introduce a sample 
solution. A typical voltage for migration was $20.0 \pm$ $0.1 \mathrm{kV}$.

\section{Gel-filtration}

An eluting solution was loaded with a Shimadzu LC6A type HPLC pump, and passed through a Sephadex G75 column $(1.5 \mathrm{~cm}$ i.d. $\times 50 \mathrm{~cm})$. The solution was then fractionated with a Toyo SF-100G fraction collector. Bile-salt in the respective fraction was determined by measuring the fluorescence intensity of the product caused from a $3 \alpha$-hydroxy steroid dehydrogenasediaphorase combined enzymatic reaction in which the substrates were NAD and resazurin, respectively. ${ }^{11}$

\section{Measurement of critical micelle concentration}

The critical micelle concentration (cmc) of the bile-salt was determined by measuring the enhanced fluorescence intensity of 8-anilino-1-naphthalenesulfonate sodium salt in an aqueous buffer solution of $0.02 \mathrm{M}$ CAPS containing prescribed amounts of bile salt. ${ }^{12}$

\section{Results and Discussion}

\section{Estimation of binding constants}

The variation of the chromatograms with and without micelles are clearly illustrated in Fig. 1, where different migration patterns can be observed. The migration times of four proteins with the micelles are greater than those without micelles, obviously indicating protein binding with the bile-salt micelles. The difference in the migration time suggests that the chemical natures of the protein-micelle interactions are dependent on the kind of proteins.

A qualitative description of the interactions of proteins with surfactants (or micelles) was made by Tanford $e t$ al. $6,7,13$ For example, SDC molecules strongly bind to specific sites onto albumin. However, additional SDC molecules do not cooperatively bind to the surface of albumin. In contrast, cytochrome $b_{5}$ has no specific sites for SDC, but can interact with SDC aggregates in a higher SDC concentration region. In some cases, one protein molecule may interact with a number of SDC aggregates. Tanford's study suggests that the interaction of surfactant molecules (or micelles) with proteins is largely dependent on the kind of proteins or micelles, or their combination. Therefore, a quite complicate model is required for representing the interactions between proteins and bile-salt micelles.

To a first approximation, we simplify the interaction as the binding of a negatively charged protein with a bilesalt micelle. The protein-micelle interaction can be evaluated in the same manner as that for the interactions of small charged molecules with micelles. ${ }^{10}$ An expanded view of a capillary column of MEKC, depicting mass-transport phenomena, is illustrated in Fig. 2. When a high voltage is applied to both ends of the column, an electroosmotic flow occurred from the positive to the negative ends, while negatively charged

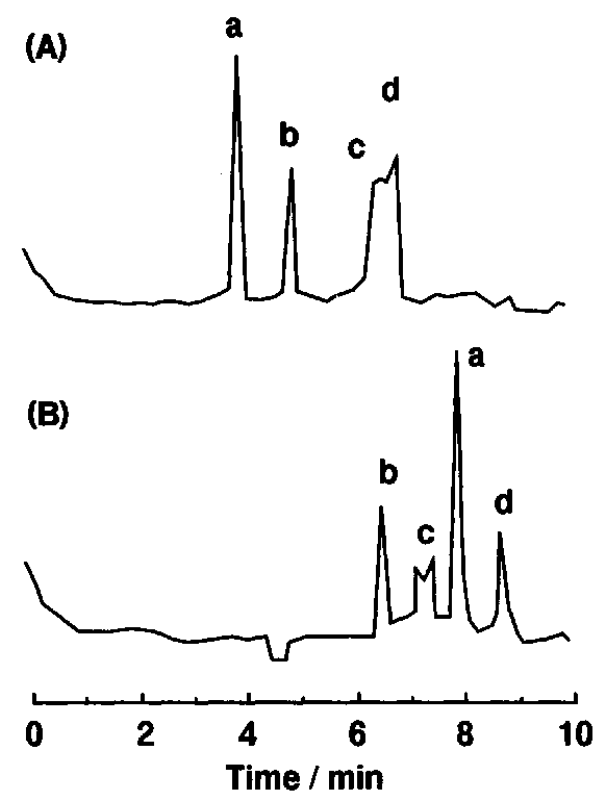

Fig. 1 MEKC chromatogram of proteins. [SDC]: (A) $0 \mathrm{mM}$, (B) $58 \mathrm{mM}$. Protein: (a) lysozyme, (b) cytochrome $c$, (c) ovalbumin, (d) albumin.

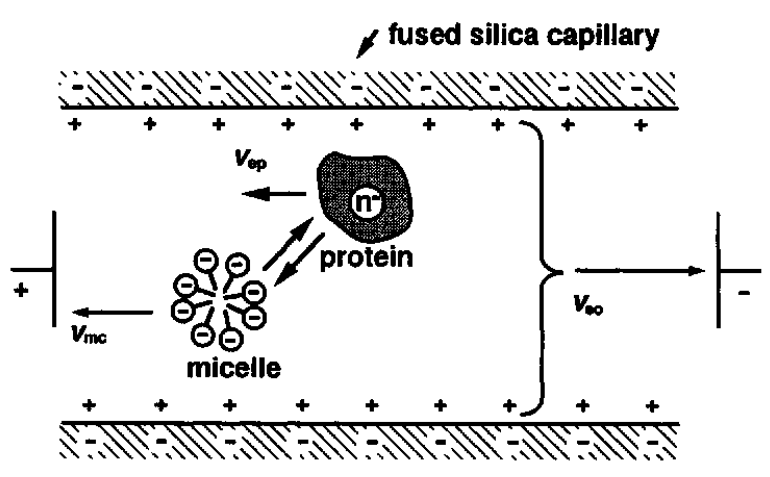

Fig. 2 Expanded view of the column dynamics.

micelles were dynamically immobilized, due to electrophoretic migration in the opposite direction. The migration velocity of a negatively charged protein $(P)$ is influenced simultaneously by the electrophoretic force and the interaction with the micelles.

The capacity factor $\left(k^{\prime}\right)$ of a negatively charged protein can be represented by

$$
k^{\prime}=\left(v_{\mathrm{eo}}+v_{\mathrm{ep}}-v_{\mathrm{p}}\right) /\left(v_{\mathrm{p}}-v_{\mathrm{mc}}\right){ }^{10}
$$

Here, $v_{\mathrm{eo}}$ is the electroosmotic velocity, $v_{\mathrm{ep}}$ the electrophoretic velocity of the protein, $v_{\mathrm{p}}$ the apparent velocity of the protein, and $v_{\mathrm{mc}}$ the velocity of micelle. They can be calculated by

$$
v_{\mathrm{eo}}=L / t_{\mathrm{eo}} ; v_{\mathrm{ep}}=L / t_{\mathrm{p}(\mathrm{cmc})}-v_{\mathrm{eo}} ; v_{\mathrm{p}}=L / t_{\mathrm{p}} ; v_{\mathrm{mc}}=L / t_{\mathrm{mc}},
$$


where $L$ is the capillary length from the inlet to the detector; $t_{\mathrm{eo}}, t_{\mathrm{mc}}$ and $t_{\mathrm{p}}$ are the migration times of the solvent, micelles and protein, respectively. The subscript $(\mathrm{cmc})$ means the absence of micelles. The values of $\mathrm{cmc}$ for the respective bile-salts obtained in this study were $12.5 \mathrm{mM}$ for $\mathrm{SC}, 7.2 \mathrm{mM}$ for SDC, $12.5 \mathrm{mM}$ for STC, and $4.6 \mathrm{mM}$ for STDC, respectively.

The shape and size of the micelles are expected to be largely dependent on the kind of bile salt. Furthermore, a protein has a larger size than does a bile-salt micelle, and, hence, a protein is hardly incorporated into a micelle. Thus, we use a binding constant for representing the protein-micelle interaction rather than a distribution constant.

Since the bile salt is in large excess, the binding constant is defined by

$$
K_{\mathrm{b}}=\left[\mathrm{P}_{\mathrm{b}}\right] /\left(\left[P_{\mathrm{w}}\right][\mathrm{B}]\right)
$$

where $\left[P_{b}\right]$ is the concentration of protein binding with the bile salt, $\left[P_{w}\right]$ the free protein concentration, and $[B]$ the concentration of the bile salt exceeding the $\mathrm{cmc} .^{14}$ The distribution constant $(K)$ of a protein between the micellar and aqueous phases is given by

$$
K=[\mathrm{P}]_{\mathrm{b}} /[\mathrm{P}]_{\mathrm{w}},
$$

if $[P]_{b}$ and $[P]_{w}$ are defined as the concentration of the protein in the micellar and aqueous phases. The capacity factor $\left(k^{\prime}\right)$ can be related to the distribution constant $(K)$ through

$$
k^{\prime}=K V_{\mathrm{mc}} / V_{\mathrm{aq}}=K v[\mathrm{~B}] /(1-v[\mathrm{~B}])
$$

where $V_{\mathrm{mc}}$ and $V_{\mathrm{aq}}$ are the volumes of the micellar and aqueous phases, and $v$ is the partial specific volume of the micelle. ${ }^{9}$ Under these experimental conditions, since the volume fraction of the micellar phase is very small, the denominator on the right side of Eq. (4) can be approximated to be equal to unity, i.e.

$$
k^{\prime} \fallingdotseq K v[\mathrm{~B}]
$$

Similarly, $[\mathrm{P}]_{w}$ can be approximate to be $\left[\mathrm{P}_{\mathrm{w}}\right]$.

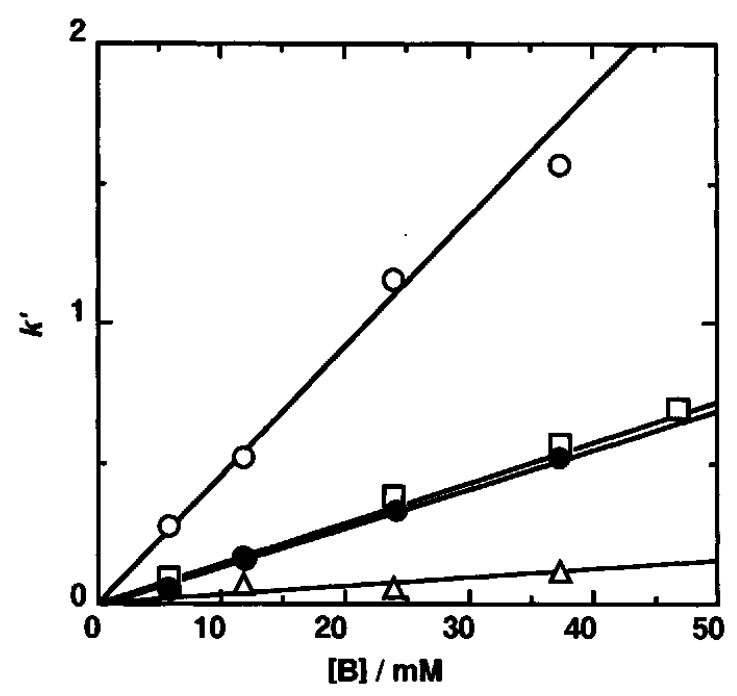

Fig. 3 Relationship between $\boldsymbol{k}^{\prime}$ and [B]. Protein: lysozyme $(O)$, cytochrome $c(\square)$, ovalbumin $(\odot)$, albumin $(\Delta)$.

$$
[\mathrm{P}]_{\mathrm{w}}=\left[\mathrm{P}_{\mathrm{w}}\right] /(1-v[\mathrm{~B}]) \doteqdot\left[\mathrm{P}_{\mathrm{w}}\right]
$$

Since $[\mathrm{P}]_{\mathrm{b}}$ is defined as the concentration of the protein in the micellar phase, it can be represented using $\left[P_{b}\right]$,

$$
[\mathrm{P}]_{\mathrm{b}}=\left[\mathbf{P}_{\mathrm{b}}\right] / V_{\mathrm{mc}}=\left[\mathbf{P}_{\mathrm{b}}\right] /(v[\mathrm{~B}]) \text {. }
$$

When Eqs. (6) and (7) are substituted to Eq. (3), the distribution constant can be related to the binding constant,

$$
K \fallingdotseq\left[\mathrm{P}_{\mathrm{b}}\right] /\left(\left[\mathrm{P}_{\mathrm{w}}\right] v[\mathrm{~B}]\right)=K_{\mathrm{b}} / v
$$

From Eqs. (5) and (8), we obtain

$$
k^{\prime} \fallingdotseq K_{\mathrm{b}}[\mathrm{B}]
$$

In Fig. 3, linear relationships were obtained between $k^{\prime}$ and [B] for all of the proteins tested. From the slopes of the curves, the values of $K_{\mathrm{b}}$ were obtained. They are

Table 1 Binding constants of protein to bile acid

\begin{tabular}{lrrrrr}
\hline \multicolumn{1}{c}{ Protein } & \multicolumn{1}{c}{ SDC } & \multicolumn{1}{c}{ STDC } & SC & STC & SDC $^{\mathrm{a}}$ \\
\hline Albumin & $13.9 \pm 0.1$ & $21.6 \pm 0.3$ & - & - & $14.5 \pm 1.3$ \\
Ovalbumin & $3.9 \pm 0.3$ & $3.9 \pm 1.0$ & - & - & $2.7 \pm 1.1$ \\
Myoglobin & $33.7 \pm 1.3$ & $17.8 \pm 1.0$ & - & - & \\
Cytochrome $c$ & $16.8 \pm 1.0$ & $13.6 \pm 0.4$ & $4.9 \pm 1.0$ & $0.0 \pm 0.2$ & \\
Lysozyme & $47.8 \pm 0.3$ & $34.0 \pm 0.2$ & $16.8 \pm 0.9$ & $6.9 \pm 1.1$ & $42.4 \pm 7.2$ \\
Hemoglobin $\alpha$ & $25.6 \pm 1.0$ & $20.5 \pm 0.5$ & - & - & \\
Hemoglobin $\beta$ & $19.8 \pm 2.3$ & $18.1 \pm 0.6$ & - & - & \\
Cytochrome P450 & $41.5 \pm 0.9$ & $34.1 \pm 0.6$ & - & - & \\
Cytochrome $b_{5}$ & $73.4 \pm 1.3$ & $136.8 \pm 2.6$ & - & & \\
\hline
\end{tabular}

a. Data obtained by gel filtration method. 


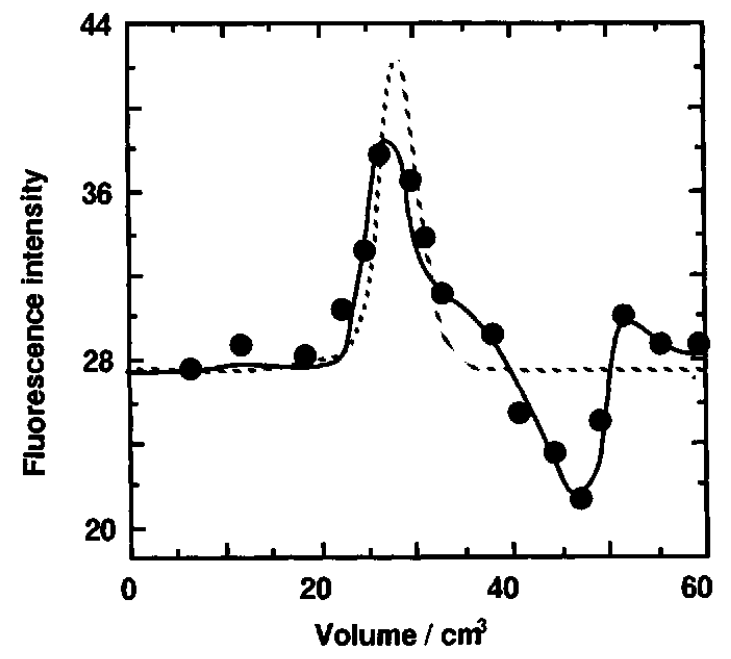

Fig. 4 Gel-chromatogram of lysozyme (dotted line) and SDC. The $Y$-axis is the fluorescence intensity of the product formed from resazurine by a combined enzymatic reaction of $3 \alpha$-hydroxysteroid dehydrogenase and diaphorase.

summarized in Table 1 , together with $K_{\mathrm{b}}$ for the other bile salts.

\section{Comparison with $K_{b}$ determined by the gel-filtration method}

The $K_{\mathrm{b}}$ values obtained in the present study may include errors, because a high electric field (typically $20 \mathrm{kV} / 65 \mathrm{~cm}$ ) can influence the orientation or shape of large protein molecules. Indeed, it is well known that the orientation of large DNA molecules is seriously influenced by the electric field in conventional gel electrophoresis. ${ }^{15,16}$ The change in the mobility of the micelle bound with relatively large protein molecules is another source of errors. Such errors can not be prevented when $K_{\mathrm{b}}$ is to be estimated from the retention time of the protein.

An attractive alternative is a gel-filtration method of Hummel and Dreyer ${ }^{17}$, which has usually been employed for determining the binding constant of small molecules to proteins. ${ }^{7,13,17-22}$ Since the binding constant is calculated from the peak area of the chromatogram, it should be free from experimental errors, as described above. Figure 4 shows the gel-chromatogram of lysozyme (dotted line) when an aqueous buffer solution of $50 \mathrm{mM}$ SDC was used for the mobile phase. In the chromatogram of SDC, a positive peak appears at the eluting position of lysozyme, and a negative peak follows the peak. This fact is indicative of the specific interaction between lysozyme and SDC.

From the area of a negative peak at different bile salt concentrations, we can calculate the concentration ratio of a protein bound with a bile salt in micelles to the total proteins, $\nu=\left[\mathbf{P}_{\mathrm{b}}\right] /\left(\left[\mathbf{P}_{\mathrm{w}}\right]+\left[\mathbf{P}_{\mathrm{b}}\right]\right)$. If $K_{\mathrm{b}}$ is represented by $\nu$, we obtain

$$
\nu /[\mathrm{B}]=K_{\mathrm{b}}(1-\nu)
$$

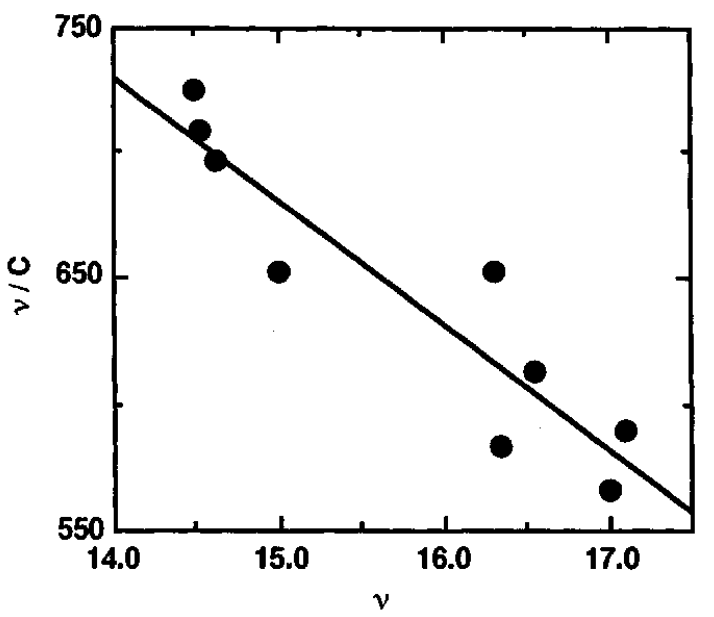

Fig. 5 Scatchard plot for the binding of lysozyme by the SDC micelle.

The values of $K_{\mathrm{b}}$ obtained from the slope of $\nu /[\mathrm{B}]$ against $\nu$ (Scatchard plot) ${ }^{23}$, as shown in Fig. 5, are listed in Table 1. They are almost the same as the values obtained by MEKC, indicating the validity of $K_{\mathrm{b}}$ determined by MEKC.

\section{Influence of hydrophobic properties to $K_{b}$}

Table 1 apparently shows that the magnitudes of $K_{\mathrm{b}}$ for cytochrome $c$ and lysozyme with SDC are greater than those with SC. SDC, having two hydroxyl groups, is more hydrophobic than SC, having three hydroxyl groups. Indeed, the values of the hydrophilic-lipophilic balance (HLB) were 11.9 for SC and 9.5 for SDC, respectively, when they were calculated on the basis of Oda's method. ${ }^{24}$ Similarly, the $K_{\mathrm{b}}$ values with STDC are greater than those with STC (HLB: 16.2 for STC, 14.0 for STDC). These facts indicate that the hydrophobic interaction plays an important role in the protein-micelle interaction. In contrast, $K_{\mathrm{b}}$ of a certain protein with SDC is not always greater than that with STDC, although the free bile acid is more hydrophobic than the tauroconjugated one. The hydrophobicity of only the bileacid moiety is important for the protein-micelle interaction.

The hydrophobic property of a protein can be represented by the hydropathy index. The index was calculated from the hydrophobicities of amino acids while taking into account the probability of their surface location. ${ }^{25}$ In Fig. 6, there is a rough, but apparent, correlation between logarithmic $K_{\mathrm{b}}$ and the hydropathy index. A similar tendency was also observed when a comparison was performed in the STDC system. These facts strongly support the idea that the predominating factor of the protein-micelle interaction is a hydrophobic interaction.

However, $\log K_{\mathrm{b}}$ of albumin is less than that expected from the correlation. As mentioned above, bile salts do not cooperatively interact with the surface of albumin, 


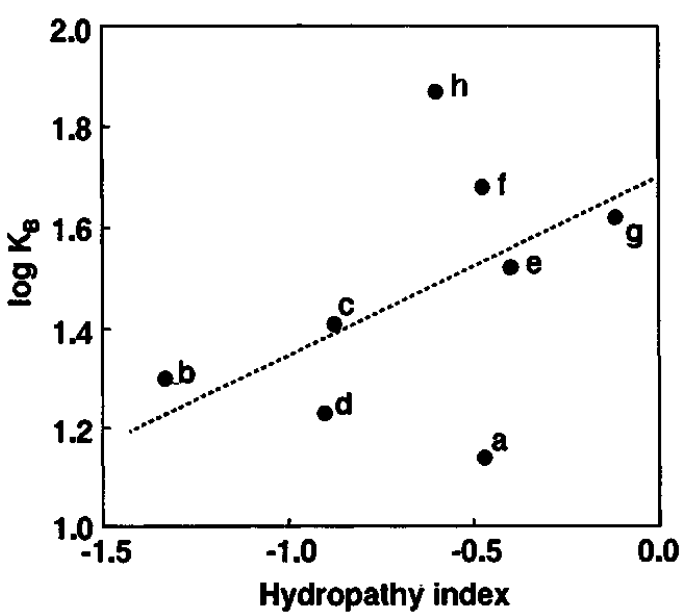

Fig. 6 Relationship between the logarithmic binding constant and the hydropathy index of protein. Protein: (a) albumin, (b) hemoglobin $\beta$, (c) hemoglobin $\alpha$, (d) cytochrome $c$, (e) myoglobin, (f) lysozyme, (g) cytochrome P450, (h) cytochrome $b_{5}$.

although some bile-salt molecules strongly bind to its specific sites. Such binding may weaken the interaction between the bile salt and albumin. On the other hand, $\log K_{\mathrm{b}}$ of cytochrome $b_{5}$ is much greater than that expected from the correlation. Since cytochrome $b_{5}$ has a large hydrophobic domain, cooperative binding of the surfactant aggregates with the hydrophobic domain enhances the interaction between cytochrome $b_{5}$ and the bile-salt micelle. The fazzy correlation between $\log K_{\mathrm{b}}$ and the hydropathy index is also ascribable to the difference in the electrostatic repulsive forces between negatively charged proteins and micelles.

Finally, it has to be mentioned that SDC is a useful surfactant for solubilizing cytochromes $\mathrm{P} 450$ and $b_{5}$ from microsomal membranes. ${ }^{3,26}$ SDC has also been employed for eluting these proteins in a column chromatographic separation. ${ }^{3,26}$ The relatively great binding constants of cytochromes $\mathrm{P} 450$ and $b_{5}$ obtained in this study suggest that SDC is a good choice for utilization in the membrane solubilization or column chromatographic elution of these proteins. Quantitative description of the proteinmicelle interaction, as proposed in the present study, would provide useful insight concerning micellarmediated separation systems.

This work was supported by a Grant-in-Aid for Scientific Reseach (No. 06453108) from Ministry of Education, Science and Culture, for which the authors are greatly thankful.

\section{References}

1. O. T. Jones, J. P. Earnest, M. G. McNamee, in "Biological Membranes: Practical Approach", ed. J. B. C. Findlay and W. H. Evans, p. 139, IRL Press, Oxford, 1987.

2. Y. Banno, Y. Yada and Y. Nozawa, J. Biol. Chem., 263, 11459 (1987).

3. T. Kamataki, K. Maeda, Y. Yamazoe, T. Nagai and R. Kato, Biochem. Biophys. Res. Commnun., 103, 1 (1981).

4. D. L. Foster and R. H. Fillingame, J. Biol. Chem., 254, 8230 (1979).

5. H. Hirata, N. Sone, M. Yoshida and K. Kagawa, Biochem. Biophys. Res. Commun., 69, 665 (1976).

6. N. C. Robinson and C. Tanford, Biochemistry, 14, 369 (1975).

7. S. Makino, J. A. Reynolds and C. Tanford, J. Biol Chem., 248, 4926 (1973).

8. S. Terabe, K. Otsuka, K. Ichikawa, A. Tsuchiya and T. Ando, Anal. Chem., 56, 111 (1984).

9. S. Terabe, K. Otsuka and T. Ando, Anal. Chem., 57, 834 (1985).

10. K. Otsuka, S. Terabe and T. Ando, J. Chromatogr., 348, 39 (1985).

11. F. Mashige, K. Imai and T. Osuga, Clin. Chim. Acta, 70, 79 (1976).

12. E. D. Vendittis, G. Palumbo, G. Parlato and V. Bocchini, Anal. Biochem., 115, 278 (1981).

13. J. A. Reynolds and R. H. Simon, J. Biol. Chem., 249, 3937 (1974).

14. E. Pramauro, G. Saini and E. Pelizzetti, Anal. Chim. Acta, 166, 233 (1984).

15. D. C. Scwarz and C. R. Cantor, Cell, 37, 67 (1984).

16. T. Y. Zhang, C. L. Smith and C. R. Cantor, Nucleic Acids Res., 19, 1291 (1991).

17. J. P. Hummel and W. J. Dreyer, Biochem. Biophys. Acta, 63, 530 (1962).

18. G. F. Fairclough, Jr. and J. S. Fruton, Biochemistry, 5, 673 (1966).

19. G. C. Wood and P. F. Cooper, Chromatogr. Rev., 12, 88 (1970).

20. W. Hoffman and U. Westphal, Anal. Biochem., 32, 48 (1969).

21. J. Clausen, J. Pharmacol. Exp. Terap., 153, 167 (1966).

22. P. Acad, D. M. Brown, T. L. Hardy and K. R. L. Mansford, Nature [London], 199, 758 (1963).

23. G. Scatchard, Ann. N. Y. Acad. Sci., 51, 660 (1949).

24. R. Oda, Teijin Times, 22, 10 (1952).

25. J. Kyte and R. F. Doolottle, J. Mol. Biol., 157, 105 (1982).

26. Y. Funae and S. Imaoka, Biophys. Biochim. Acta, 842, 119 (1985).

(Received February 7, 1996)

(Accepted May 13, 1996) 